\title{
Systematic Review on the Acute Cost-of-Illness of Sepsis and Meningitis in Neonates and Infants
}

\author{
Omar Salman, MSc, * Simon R. Procter, Dphil, * Callum McGregor, MSc*, Proma Paul, DrPH, * \\ Raymond Hutubessy, PhD, † Joy E. Lawn, PhD, * and Mark Jit, PhD, * $¥ \S$
}

Background: Sepsis and meningitis in neonates and infants are a source of substantial morbidity, mortality and economic loss. The objective of this review is to estimate the acute costs associated with treating sepsis, meningitis and meningococcal septicemia, in neonates and infants, worldwide. Methods: The electronic databases Medline, Embase and EconLit were searched and exported on November 24, 2018. Studies that reported an average hospitalization cost for confirmed cases of sepsis, meningitis or meningococcal septicemia were eligible for our review. Descriptive data were extracted and reported costs were inflated and converted. A narrative synthesis of the costs was conducted.

Results: Our review identified 20 studies reporting costs of sepsis, meningitis and/or meningococcal septicemia. Costs ranged from $\$ 55$ to $\$ 129,632$ for sepsis and from $\$ 222$ to $\$ 33,635$ for meningitis (in 2017 US dollars). One study estimated the cost of meningococcal septicemia to be $\$ 56,286$. All reported costs were estimated from the perspective of the healthcare provider or payer. Most studies were from the United States, which also had the highest costs. Only a few studies were identified for low- and middleincome countries, which reported lower costs than high-income countries for both sepsis and meningitis.

Conclusions: Sepsis and meningitis in neonates and infants are associated with substantial costs to the healthcare system and showed a marked difference across global income groups. However, more research is needed to inform costs in low- and middle-income settings and to understand the economic costs borne by families and wider society.

Key Words: neonate, infants, sepsis, meningitis, costs

(Pediatr Infect Dis J XXX;XX:00-00)

nfectious diseases among neonates and infants constitute a considerable global health burden. Despite significant strides in enhancing childhood survival over recent decades, there remain around 5.4 million deaths annually in children under 5, with 2.5

Accepted for publication September 20, 2019.

From the *London School of Hygiene and Tropical Medicine (LSHTM), Department of Infectious Diseases Epidemiology, London, United Kingdom; $\dagger$ Department of Immunization, Vaccines and Biologicals, World Health Organization, Geneva, Switzerland; \$Modelling and Economics Unit, Public Health England, London, United Kingdom; and §Division of Epidemiology and Biostatistics, School of Public Health, University of Hong Kong, Hong Kong SAR, China.

Supported by The Bill \& Melinda Gates Foundation, Seattle, WA (OPP1180644 and OPP1157270).

O.S. and S.R.P. contributed equally

Address for correspondence: Mark Jit, PhD, London School of Hygiene and Tropical Medicine (LSHTM), Department of Infectious Diseases Epidemiology, London, United Kingdom. E-mail: mark.jit@1shtm.ac.uk

Supplemental digital content is available for this article. Direct URL citations appear in the printed text and are provided in the HTML and PDF versions of this article on the journal's website (www.pidj.com).

Copyright (C) 2019 The Author(s). Published by Wolters Kluwer Health, Inc. This is an open access article distributed under the Creative Commons Attribution License 4.0 (CCBY), which permits unrestricted use, distribution, and reproduction in any medium, provided the original work is properly cited

ISSN: 0891-3668/19/XXXX-0000

DOI: $10.1097 /$ INF.0000000000002500 million deaths amongst neonates. ${ }^{1}$ An estimated one-third of neonatal deaths are caused by infectious causes, with limited data on the etiological agents behind these infections. ${ }^{2}$ Meningitis and sepsis are consequences of several invasive bacterial species such as group B streptococcus, Neisseria meningitides and Streptococcus pneumoniae and are particularly common in young children. They have a high case-fatality risk, collectively accounting for an estimated 3.7 deaths per 1000 live births, ${ }^{3}$ and impact substantially on child survival where $7 \%$ of under- 5 mortality is attributable to these conditions. ${ }^{3}$ They also commonly cause long-term physical and neurological sequelae among survivors.

Costs of treating sepsis and meningitis can vary according to healthcare setting, age and severity of infection. Costs incurred in treating meningitis significantly decrease with increasing age of child, as well as increasing certainty of diagnosis. ${ }^{4}$ A similar trend is seen with sepsis where infants can incur almost double the cost of treatment compared to children over one year old. ${ }^{5}$ This is because of the severity of infection in younger children who have underdeveloped immune systems compared to older children. Although existing studies report a wide range of costs across low-, middle- and highincome countries, the literature has not been reviewed systematically to present a global comparison of costs incurred as a result of sepsis and meningitis in neonates and infants. Moreover, it is estimated that three-quarters of reported deaths amongst under- $5 \mathrm{~s}$ occur in the first year of life, ${ }^{1}$ requiring a better understanding of the age-specific attributable costs, where studies typically aggregate costs for all children under 5 despite variations in setting, severity and age.

Much of the burden of sepsis and meningitis could be prevented or reduced in severity by measures such as current and pipeline vaccines, diagnostics and antibiotics. In low- and middleincome settings it has been proposed that scaling up coverage of facility-based healthcare services during the antenatal period, labor and childbirth could avert close to $70 \%$ of neonatal deaths by $2025 .{ }^{6}$ However, investment in the optimal prevention and treatment strategies require good estimates of the cost-effectiveness of the interventions, which in turns requires understanding the economic burden of sepsis and meningitis. As important short-term landmarks of invasive neonatal and infant disease, costs of treating meningitis and sepsis can instruct economic evaluations conducted by different stakeholders in order to optimize scarce health care resources.

The objective of this study was to conduct a systematic review to identify and assess the worldwide evidence on the costs of treating sepsis, meningitis and meningococcal septicemia, among neonates and infants under one.

\section{MATERIALS AND METHODS}

\section{Search Strategy}

Our review was carried out in accordance with the Preferred Reporting Items for Systematic Reviews and Meta-Analyses guidelines, and a protocol for the review was registered in International prospective register of systematic reviews (CRD42019120253). We performed a systematic search of the Medline, Embase and Econlit bibliographic databases to identify studies reporting the acute costs of treating neonates and infants under 1 year old with confirmed 
sepsis and meningitis. The search strategy combined index terms and key words, including "infant," neonate," "sepsis," "meningitis" and "cost," and the full search terms are provided in Text, Supplemental Digital Content 1, http://links.lww.com/INF/D666. The search was conducted on November 24, 2018

\section{Selection Criteria}

Since there is no single accepted clinical definition of sepsis, ${ }^{7}$ sepsis and meningitis were defined according to the case definition used by the authors of each article. Cases with severe septic shock were also included in our case definition; however, we excluded cases of aseptic meningitis and rule-out sepsis. Where studies ascertained cases through coding systems, such as the International Classification of Diseases, we assumed that coding correctly reflected clinical presentation and confirmed laboratory isolation of infectious organisms. Cases with meningococcal septicemia were also considered for our review and were reported as a subset of meningitis. Our selection was limited to human subjects and studies that estimated costs based on unit costs or resource utilization measures derived from primary data collection or previously unanalyzed data from healthcare information systems. We excluded review articles and reported costs that were not directly attributable to the age group and/or exposure of interest. No limits were applied to conference abstracts or non-English studies.

\section{Study Selection and Data Extraction}

Search results were imported into a Reference Manager (Mendeley), and duplicate records were manually detected and removed. Two reviewers, O.S. and C.M., screened study titles and abstracts, and the full text of potentially eligible studies to assess their eligibility for final inclusion. Authors were contacted where data was missing or clarifications on reported costs were needed. The studies' descriptive characteristics, including study design, data sources, costing methodology and any underlying comorbidities, were recorded. We extracted all reported costs associated with an acute hospital episode for our exposure of interest, regardless of whether they fell on the healthcare provider, third-party payer, patient/household or society. Where available, we also extracted individual costs for different categories of health resources (eg, drugs and diagnostics) as well as the average length of stay (LOS).

\section{Data Analysis and Synthesis}

Reported costs were inflated to the year 2017 using the country-specific World Bank gross domestic product deflator. ${ }^{8}$ For studies that reported costs in local currencies other than US Dollars the values were first inflated then converted into US Dollars using the historical foreign exchange rates of the US Federal Reserve for 2017. ${ }^{9}$ Values were also converted to international dollars using the ratio of the Purchasing Power Parity conversion factor to market exchange rates for $2017 .{ }^{10}$

Extracted studies were subgrouped according to the World Bank Country and Lending Group categorization for 2019. ${ }^{11}$

\section{Quality Assessment}

Criteria to assess methodological strengths and weaknesses in study design were adapted from a previous meningitis costing review by Portnoy et a $1^{12}$ We used the 5-point scale after revising the methodological criteria to better reflect the global focus and selection criteria of our review (ie, disregarding country setting and costs based on interviews). The 5 selected factors that increase the assessment of a study's quality were (1) using a bottom-up approach to estimating costs, (2) a study sample that exceeds 100 patients, (3) reporting both direct and indirect costs, (4) inclusion of a specific clinical case definition for sepsis and/or meningitis and (5) the specification of measures taken by authors to account for acknowledged uncertainties and biases. A study was awarded 1 point for each of these factors resulting in a total score between 0 and 5. No points were awarded for a factor that was unclear from the authors' description of the study.

\section{RESULTS}

\section{Study Selection}

Figure, Supplemental Digital Content 2, http://links.lww. com/INF/D667 is a Preferred Reporting Items for Systematic Reviews and Meta-Analyses flow diagram showing the process by which studies were selected. Our search yielded 3441 studies after searching our selected databases.

A total of 20 studies met the inclusion criteria of our review, ${ }^{4,5,13-30}$ and the main study characteristics are summarized in Table 1 . The included studies had very limited geographic coverage with cost estimates for sepsis from 5countries and meningitis estimates from only 2 countries. Overall, 13 studies were from North America with only 4 studies from East Asia, 1 study from Southern Asia, 1 study from North Africa and 1 study from Europe. There were no study studies from either Latin America or sub-Saharan Africa. Five studies were from middle-income countries and 15 studies from high-income settings. No studies were from low-income countries.

Each study included one or more treatment cost estimates for sepsis, meningitis and/or meningococcal septicemia, and overall 24 cost estimates were reported across the 3 diseases. Four studies reported costs for treating patient with sepsis in populations with particular comorbidities. All the studies reported costs from the healthcare provider perspective, with the exception of 3 studies, which provided a payer's perspective..$^{23,27,28}$ There were no studies that included costs from a wider societal perspective, and none of the included studies reported long-term costs associated with sequelae of sepsis or meningitis.

Studies reported a mixture of mean and median costs. Where a study reported both estimates, we have presented the mean cost in Figures 1 and 2 and include the median in Table, Supplemental Digital Content 3, http://links.lww.com/INF/D668.

\section{Costs Related to Sepsis}

There were 17 estimates for sepsis-related costs (see Fig. 1).

\section{Average Cost of Hospitalization}

Among the reported estimates, 14 studies gave an average cost for an entire hospital episode. The costs of treating sepsis per patient ranged from $\$ 55$ in India ${ }^{13}$ to $\$ 129,632$ in the United States. ${ }^{18}$ The mean cost weighted by study sample size (and ignoring those studies that only reported median costs) was $\$ 55$ in lowermiddle income countries, \$2192 in upper-middle income countries and $\$ 82,328$ in high-income countries.

\section{Component Costs}

In addition to the total cost of hospitalization, 2 studies separately reported the average cost of antimicrobial therapy per patient. ${ }^{14,27}$

\section{Costs for Patients With Specific Comorbidities}

Four studies gave an estimate of sepsis costs in study populations with particular comorbidities..$^{19,26,29,30}$ Willson et $\mathrm{al}^{30}$ found a cost of $\$ 36,580$ in infants with sepsis who had underlying bronchiolitis. Robinson et al's ${ }^{26}$ study in population of newborns born by repeat cesarean reported the highest average costs of all our included studies

Two studies in patients with gastroschisis used regression analysis to estimate the additional costs for those patients who also developed sepsis ${ }^{19,29}$ compared with patients without sepsis. Both 
TABLE 1. Summary of Included Studies, Classified by Country Income Level ( $\mathrm{n}=20)$

\begin{tabular}{|c|c|c|c|c|c|c|c|c|c|}
\hline Study & Year & Country & $\begin{array}{c}\text { Costing } \\
\text { Methodology }\end{array}$ & $\begin{array}{c}\text { Cost } \\
\text { Setting }\end{array}$ & Perspective & $\begin{array}{c}\text { Costs } \\
\text { Categories }\end{array}$ & Condition(s) & $\begin{array}{c}\text { Case } \\
\text { Ascertainment }\end{array}$ & Age Range \\
\hline Anh et $\mathrm{al}^{4}$ & 2010 & Vietnam & Hospital charges* & Hospital & Provider & Single & Meningitis & $\begin{array}{l}\text { Laboratory } \\
\text { confirmed }\end{array}$ & $<1$ year \\
\hline Garg et $\mathrm{al}^{13}$ & 2005 & India & Unspecified & ICU only & Provider & Single & Sepsis & Unspecified & "Neonates" \\
\hline Atif et $\mathrm{al}^{14}$ & 2008 & Algeria & $\begin{array}{l}\text { Prospective } \\
\text { microcosting }\end{array}$ & ICU only & Provider & Multiple & Sepsis & $\begin{array}{c}\text { Clinical and } \\
\text { laboratory } \\
\text { confirmed }\end{array}$ & 0-89 days \\
\hline Liao X-P et al ${ }^{15}$ & 2017 & China & $\begin{array}{l}\text { Patient-level cost } \\
\text { accounts }\end{array}$ & Hospital & Provider & Single & Sepsis & Unspecified & "Newborns" \\
\hline Qian et $\mathrm{al}^{16}$ & 2008 & China & $\begin{array}{l}\text { Prospective } \\
\text { microcosting }\end{array}$ & Hospital & Provider & Single & Sepsis & Unspecified & $0-89$ days \\
\hline Angus et $\mathrm{al}^{5}$ & 2001 & United States & Hospital charges* & Hospital & Provider & Single & Sepsis & ICD codes & $<1$ year \\
\hline Balada-Llasat et $\mathrm{al}^{17}$ & 2019 & United States & Hospital charges* & Hospital & Provider & Multiple & Meningitis & ICD codes & $<1$ year \\
\hline Balamuth et $\mathrm{al}^{18}$ & 2014 & United States & Hospital charges* & Hospital & Provider & Single & Sepsis & ICD codes & $0-59$ days \\
\hline Bhatt et $\mathrm{al}^{19} \dagger$ & 2018 & United States & Hospital charges* & Hospital & Provider & Single & Sepsis & ICD codes & 0-28 days \\
\hline Davis et $\mathrm{al}^{20}$ & 2011 & United States & Hospital charges* & Hospital & Provider & Single & $\begin{array}{l}\text { Meningitis }+ \\
\text { meningococcal } \\
\text { septicemia }\end{array}$ & ICD codes & $<1$ year \\
\hline Donovan et $\mathrm{al}^{21}$ & 2013 & United States & $\begin{array}{l}\text { Patient-level cost } \\
\text { accounts }\end{array}$ & ICU only & Provider & Single & Sepsis & Unspecified & $<120$ days \\
\hline Hartman et $\mathrm{al}^{22}$ & 2013 & United States & Hospital charges* & Hospital & Provider & Single & Sepsis & ICD codes & "Newborns" \\
\hline Iñigo et $\mathrm{al}^{23}$ & 2006 & Spain & Government tariffs & Hospital & Payer & Single & Sepsis & ICD codes & $<1$ year \\
\hline Johnson et $\mathrm{al}^{24}$ & 2013 & United States & $\begin{array}{l}\text { Patient-level cost } \\
\text { accounts }\end{array}$ & ICU only & Provider & Single & Sepsis & ICD codes & "Newborns" \\
\hline Lieu et $\mathrm{al}^{25} \ddagger$ & 1992 & United States & Hospital charges* & Hospital & Provider & Single & $\begin{array}{l}\text { Meningitis + } \\
\text { sepsis }\end{array}$ & Unspecified & $\begin{array}{l}28-90 \\
\text { days }\end{array}$ \\
\hline Robinson et $\mathrm{al}^{26 \dagger}$ & 2010 & United States & Hospital charges* & Hospital & Provider & Single & Sepsis & ICD codes & 0-89 days \\
\hline Tanihara et $\mathrm{al}^{27}$ & 2014 & Japan & $\begin{array}{l}\text { Health insurance } \\
\text { claims }\end{array}$ & Hospital & Payer & Single & Sepsis & ICD codes & 0-95 days \\
\hline Trevejo et al ${ }^{28}$ & 2003 & United States & $\begin{array}{l}\text { Patient-level cost } \\
\text { accounts }\end{array}$ & Hospital & Payer & Single & Meningitis & ICD codes & $<1$ year \\
\hline Uribe-Leitz et $\mathrm{al}^{29} \dagger$ & 2017 & United States & Hospital charges* & Hospital & Provider & Single & Sepsis & ICD codes & $<1$ year \\
\hline Willson et $\mathrm{al}^{30} \dagger$ & 2003 & United States & $\begin{array}{l}\text { Patient-level cost } \\
\text { accounts }\end{array}$ & Hospital & Provider & Single & Sepsis & ICD codes & $<1$ year \\
\hline
\end{tabular}

*Ratio cost-to-charge applied.

$\dagger$ Costs reported for sepsis with comorbidities.

$\mp$ Costs reported separately for bacterial and viral meningitis.

ICD indicates International Classification of Diseases.

studies were conducted in the United States and reported incremental costs of $\$ 21,628$ and $\$ 22,380$.

\section{Costs Related to Meningitis and Meningococcal Septicemia}

The reported costs for meningitis and meningococcal septicemia are summarized in Figure 2.

\section{Average Cost of Hospitalization}

Five studies reported acute hospitalization costs for treating meningitis, which varied from $\$ 222$ in Vietnam ${ }^{4}$ to approximately $\$ 40,000$ in the United States. ${ }^{28}$ The mean cost weighted by study sample size was $\$ 222$ in lower-middle income countries and $\$ 13,845$ in high-income countries. One study reported separate costs for viral and bacterial meningitis ${ }^{25}$ with the reported costs for bacterial meningitis more than 3 times greater than those for viral meningitis $(\$ 13,154$ vs. \$3874).

\section{Component Costs}

Balada-Llasat et $\mathrm{al}^{17}$ was the only study that gave a breakdown of meningitis costs across different categories of health resource, reporting separate costs for antimicrobial therapy, diagnostic and laboratory tests.

\section{Cost of Meningococcal Septicemia}

One study reported a cost of $\$ 56,286$ in a group of patients with meningococcal septicemia. ${ }^{20}$

\section{Quality Appraisal}

The quality appraisal of our selected studies is summarized in Table 2. There was a wide variation in the quality of scores, with half of studies scoring 2 or less. Seven studies scored 3, 3 studies scored 4, and there were no studies that scored 5 . All the articles used an observational study design, among which, 13 used a bottom-up costing methodology to calculate their costs, retrieving estimates on resource utilization by surveying local health practitioners, local expert panels and from in-hospital accounting systems. Five studies did not provide a clear case definition.

\section{DISCUSSION}

\section{Summary of Findings}

Treatment of neonates and infants with sepsis or meningitis represent significant costs to healthcare systems. We have conducted a systematic review of studies reporting the cost of treating sepsis and/or meningitis in neonates and infants. Our review found 20 studies with costs ranging from $\$ 55$ to $\$ 129,632$ for sepsis, $\$ 222$ to $\$ 33,635$ for meningitis and a single cost estimate of $\$ 56,286$ for meningococcal septicemia.

We found that most of the literature is concentrated in highincome settings, with 13 studies in the United States compared with only 5 in middle-income countries and none at all in low-income countries. This highlights a major gap in the literature because treatment costs varied considerably across income groups. For instance, all 5 middle-income countries had sepsis treatment costs that were 


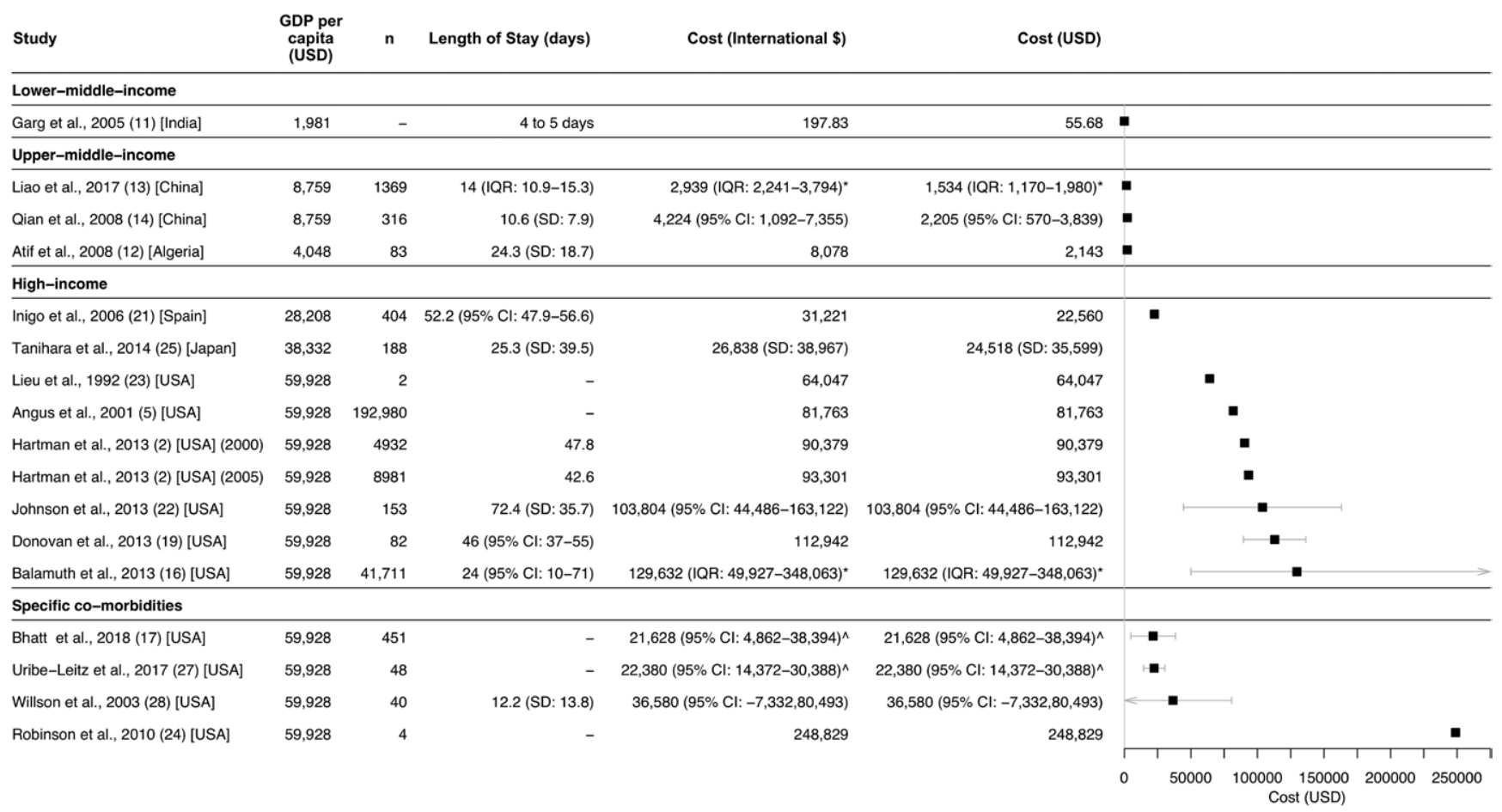

FIGURE 1. Costs related to sepsis. *Reported median as opposed to mean costs. ^Reported mean difference in costs for patients with an underlying comorbidity who developed sepsis compared to who did not. Cl indicates confidence interval; GDP, gross domestic product; IQR, interquartile range; USD, US dollars.



FIGURE 2. Costs related to meningitis and meningococcal septicemia. *Reported median as opposed to mean costs. ${ }^{\wedge}$ Viral meningitis. Bacterial meningitis. Cl indicates confidence interval; GDP, gross domestic product; USD, US dollars.

considerably lower than those in the United States $(\$ 55$ to $\$ 3607$ in middle-income countries vs. $\$ 64,047$ to $\$ 129,632$ in the United States). One factor contributing to the low number of studies from low- and middle-income countries might be the availability of electronic healthcare information systems that facilitate retrospective analysis of routinely collected patient data.

The higher reported costs for high-income countries are likely to reflect both greater underlying costs of healthcare production such as staff wages and the provision of more advanced and expensive treatment options. However, the majority of our studies did not report disaggregated costs and gave only a single estimate of the average cost in the form of incurred healthcare expenses in acute hospitalization, standard hospital care and management in neonatal and pediatric intensive care units (ICUs) (Table 1). Only 3 of our studies reported a breakdown of different resources categories, including average costs for underlying antimicrobial therapy, consultation fees and costs of diagnostics in treating each respective disease. ${ }^{14,17,27}$ LOS is also likely to be an important driver of cost differences. For sepsis, the average reported LOS was 24 to 72 days in high-income countries versus 4 to 14 days in low- and middle-income countries.

Heterogeneity in study populations and differences in study design might also have contributed to variation in the observed costs. Four studies focused only on the costs of treating patients in the ICU, ${ }^{13,14,21,24}$ whereas most included patients and costs across the hospital. There were also differences in the age ranges of included infants (Table 1.) Two studies looked at costs for preterm very low weight newborns, ${ }^{21,24}$ but few authors reported the proportion of preterm infants in their studies. A variety of different costing methodologies were employed, including microcosting and top-down approaches. In the United States, several studies used average 
TABLE 2. Summary of Study Quality Appraisal

\begin{tabular}{|c|c|c|c|c|c|c|c|c|}
\hline Study & Year & Country & $\begin{array}{l}\text { Bottom-Up } \\
\text { Costing }\end{array}$ & $\begin{array}{l}\text { Sample Size } \\
\text { Over } 100\end{array}$ & $\begin{array}{l}\text { Direct and } \\
\text { Indirect Costs }\end{array}$ & $\begin{array}{l}\text { Case Definitions } \\
\text { Included }\end{array}$ & $\begin{array}{l}\text { Controlled for } \\
\text { Acknowledged Bias }\end{array}$ & $\begin{array}{l}\text { Quality } \\
\text { Score }\end{array}$ \\
\hline Angus et $\mathrm{al}^{5}$ & 2001 & United States & $\mathrm{X}$ & $\mathrm{X}$ & & $\mathrm{X}$ & $\mathrm{X}$ & 4 \\
\hline Anh et $\mathrm{al}^{4}$ & 2010 & Vietnam & $\mathrm{X}$ & $\mathrm{x}$ & & $\mathrm{X}$ & $\mathrm{x}$ & 4 \\
\hline Atif et $\mathrm{al}^{14}$ & 2008 & Algeria & $\mathrm{X}$ & & & $\mathrm{X}$ & $\mathrm{X}$ & 3 \\
\hline Balada-Llasat et al ${ }^{17}$ & 2019 & United States & $\mathrm{X}$ & $\mathrm{X}$ & & $\mathrm{X}$ & & 3 \\
\hline Balamuth et al ${ }^{18}$ & 2014 & United States & $\mathrm{X}$ & $\mathrm{X}$ & & $\mathrm{X}$ & & 3 \\
\hline Bhatt et al ${ }^{19}$ & 2018 & United States & & $\mathrm{X}$ & & $\mathrm{X}$ & & 2 \\
\hline Davis et $\mathrm{al}^{20}$ & 2011 & United States & & & & $\mathrm{X}$ & $\mathrm{X}$ & 2 \\
\hline Donovan et $\mathrm{al}^{21}$ & 2013 & United States & $\mathrm{X}$ & & & $\mathrm{X}$ & $\mathrm{X}$ & 3 \\
\hline Garg et $\mathrm{al}^{13}$ & 2005 & India & $\mathrm{X}$ & & & & & 1 \\
\hline Hartman et $\mathrm{al}^{22}$ & 2013 & United States & $\mathrm{X}$ & $\mathrm{X}$ & & $\mathrm{x}$ & & 3 \\
\hline Iñigo et $\mathrm{al}^{23}$ & 2006 & Spain & $\mathrm{X}$ & $\mathrm{X}$ & & $\mathrm{X}$ & $\mathrm{X}$ & 4 \\
\hline Johnson et $\mathrm{al}^{24}$ & 2013 & United States & $\mathrm{X}$ & $\mathrm{X}$ & & $\mathrm{X}$ & & 3 \\
\hline Liao et $\mathrm{al}^{15}$ & 2017 & China & & $\mathrm{X}$ & & & & 1 \\
\hline Lieu et $\mathrm{al}^{25}$ & 1992 & United States & & & & & & 0 \\
\hline Qian et $\mathrm{al}^{16}$ & 2008 & China & $\mathrm{X}$ & $\mathrm{x}$ & & & & 2 \\
\hline Robinson et al ${ }^{26}$ & 2010 & United States & & & & $\mathrm{X}$ & & 1 \\
\hline Tanihara et al ${ }^{27}$ & 2014 & Japan & $\mathrm{x}$ & $\mathrm{X}$ & & $\mathrm{X}$ & & 3 \\
\hline Trevejo et al ${ }^{28}$ & 2003 & United States & & & & & & 0 \\
\hline Uribe-Leitz et al ${ }^{29}$ & 2017 & United States & & & & $\mathrm{X}$ & $\mathrm{X}$ & 2 \\
\hline Willson et al ${ }^{30}$ & 2003 & United States & & & & $\mathrm{X}$ & & 1 \\
\hline
\end{tabular}

cost-to-charge ratios to estimate costs based on fees charged to insurers. Most cost estimates were made from a healthcare provider perspective, but some studies used a payer perspective. There were also differences between studies in terms of case definition and case ascertainment. In particular, some studies used either specific or combination International Classification of Diseases codes systems to ascertain cases in regional and national databases, and authors of such studies widely acknowledged the potential for misclassification errors that might bias their findings.

There were no reports of economic costs to households or wider society, reflecting another important gap in the literature. Since none of our selected studies included indirect healthcare costs of treating sepsis, meningitis and meningococcal septicemia, this could lead to an underestimation of the true costs of treating these conditions. Although our study was not designed to find longterm costs associated with sequelae of sepsis and meningitis, none of the articles we located reported any such costs in our population of interest, which points to another important area of research.

The majority of studies we found included all infants with sepsis or meningitis who were treated within the hospital or ICU, but a few authors reported average costs of treating sepsis as a complication in infants with underlying comorbidities, including gastroschisis and salmonellosis. Some of these studies reported only the total treatment costs, including the cost of treating underlying comorbidities, but 2 studies demonstrated the substantial additional costs of treating sepsis in these populations.

The costs reported in this study are key to economic evaluations needed to understand the value of introducing vaccines against infections that causes sepsis and meningitis. Many of the countries with studies have already introduced such vaccines. Examples are pneumococcal conjugate vaccines (introduced in the United States in 2000, Japan in 2011, Algeria in 2016, parts of India in 2017 and Spain in 2018, Haemophilus influenzae type b vaccine (United States in 1991, Spain in 1998, Algeria in 2008, Vietnam in 2010, Japan in 2011 and India in 2015) and meningococcal C (Spain in 2000). ${ }^{31}$ Nevertheless, many of these vaccines are still not in routine immunization programs in much of the world. Also, while introduction of these vaccines will impact the health and economic burden of infectious disease, we do not expect this to influence unit costs of treatment amongst neonates and infants who develop sepsis or meningitis.

\section{Comparison to Previous Studies}

This is the first study to systematically review the costs of neonatal sepsis, meningitis and meningococcal septicemia globally. Two other systematic reviews of the cost of sepsis or meningitis have been published. One review examined the cost of meningitis in low- and middle-income settings. ${ }^{12}$ This gave a cost range from $\$ 42$ to $\$ 9300$ compared with $\$ 222$ in the only low- or middle-income country study (in Vietnam) in our review. In addition, we also found reported meningitis costs of $\$ 3874$ to $\$ 39,169$ in high-income countries beyond the scope of the previous review. A second review examined the cost of sepsis in all countries, finding a cost range of $\$ 20,795$ to $\$ 40,835,{ }^{32}$ compared with $\$ 55$ to $\$ 129,632$ in our review. Our review identified more studies specifically reporting costs amongst infants and neonates (16 compared with 1 study) and was carried out over an unrestricted timeframe, in contrast to the 10-year period between 2005 and 2015 for the published review. We also observed a markedly different lower bound in the cost range because our review included studies from lower-income settings. Neither of the previous reviews examined the costs of meningococcal septicemia, for which we found a single reported estimate of \$56,286. This was a considerably higher than the costs reported for meningitis alone but fell within our range of sepsis-related costs.

\section{Limitations}

One challenge in this review was the difficulty in retrieving costs for neonates and infants in studies covering a range of ages, despite writing to authors to request further information. This highlights the importance of reporting cost estimates by age group in future studies. This is particularly important since neonatal sepsis and meningitis imposes considerably higher costs than treating these conditions in older children. ${ }^{4,5}$ For instance, Anh et $\mathrm{al}^{4}$ found the average cost of treating meningitis was $\$ 190$ for infants under 5 months compared with $\$ 114$ for children 59 months of age.

Another challenge was with the consistency and clarity of case definitions for sepsis and meningitis. In particular, sepsis was not consistently defined and was sometimes used interchangeably with invasive bloodstream infections. In 4 of the included studies, there was no clearly specified case definition at all. To improve comparability future research needs to apply consistent case definitions for meningitis and sepsis, such as the "Third international consensus definitions for sepsis and septic shock," although these are not yet fully applicable for neonates. ${ }^{33}$ 
A further limitation is that we were unable to generate formal pooled cost estimates. The number of included studies was considered too few to perform meta-analysis given differences in reported estimate types (mean vs. median), the number of studies that did not report uncertainty intervals and heterogeneity between studies.

Overall, a significant number of the studies we identified were of quite poor quality and were limited in the description they provided about their costing methodology. For example, the costing perspective was rarely defined explicitly, there was varying levels of detail about how reported costs were calculated and many studies did not report uncertainty ranges for their estimates. This was especially seen in studies that did not primarily focus on conducting a detailed costing analysis and where costing was a secondary outcome in broader epidemiological studies and economic evaluations. Utilization of references cases and reporting guidelines for costing and economic evaluations would increase consistency and transparency of economic methods and the comparability of reported costs. ${ }^{34,35}$

\section{Conclusions}

Sepsis and meningitis in neonates and infants are associated with substantial costs to health care systems. Reported costs showed significant variation between different settings, although methodologic variations between studies limit the comparability of individual cost estimates. Evidence gaps identified by our study highlight the need for (1) more research on the cost of treating sepsis and meningitis in neonates and infants in low- and middleincome settings and (2) more studies that measure the economic costs of illness borne by families and wider society. Furthermore, to maximize the value of future studies, researchers need to improve consistency in case definitions and utilize comparable and well-described economic methods.

\section{REFERENCES}

1. United Nations Inter-agency Group for Child Mortality Estimation (UN IGME). Levels \& Trends in Child Mortality: Report 2018, Estimates developed by the United Nations Inter-agency Group for Child Mortality Estimation. New York, NY: United Nations Children's Fund; 2018.

2. Lawn JE, Bianchi-Jassir F, Russell NJ, et al. Group B streptococcal disease worldwide for pregnant women, stillbirths, and children: why, what, and how to undertake estimates? Clin Infect Dis. 2017;65(suppl_2):S89-S99.

3. Liu L, Oza S, Hogan D, et al. Global, regional, and national causes of under-5 mortality in 2000-15: an updated systematic analysis with implications for the sustainable development goals. Lancet. 2016;388:3027-3035.

4. Anh DD, Riewpaiboon A, Tho LH, et al. Treatment costs of pneumonia, meningitis, sepsis, and other diseases among hospitalized children in Viet Nam. J Health Popul Nutr. 2010;28:436-442.

5. Angus DC, Linde-Zwirble WT, Lidicker J, et al. Epidemiology of severe sepsis in the United States: Analysis of incidence, outcome, and associated costs of care: Crit Care Med. 2001;29:1303-1310.

6. Bhutta ZA, Das JK, Bahl R, et al; Lancet Newborn Interventions Review Group; Lancet Every Newborn Study Group. Can available interventions end preventable deaths in mothers, newborn babies, and stillbirths, and at what cost? Lancet. 2014;384:347-370.

7. Singer M, Deutschman CS, Seymour CW, et al. The third international consensus definitions for Sepsis and Septic Shock (Sepsis-3). JAMA. 2016;315:801-810.

8. The World Bank. GDP deflator (base year varies by country)| Data. Cited August 11, 2019]. Available at: https://data.worldbank.org/indicator/ NY.GDP.DEFL.ZS. Accessed 12, July 2019.

9. Board of Governors of the Federal Reserve System. The Federal Reserve Board of Governors in Washington DC. The Fed - foreign exchange rates G.5A annual. [cited July 1, 2019]. Available at: https://www.federalreserve. gov/releases/g5a/current/default.htm. Accessed 12, July 2019.

10. The World Bank. Price level ratio of PPP conversion factor (GDP) to market exchange rate | Data [Internet]. [cited August 11, 2019]. Available at: https:// data.worldbank.org/indicator/PA.NUS.PPPC.RF. Accessed on 12 July 2019.

11. The World Bank. World Bank country and lending groups - World Bank Data help desk. [cited Jul 1, 2019]. Available at: https://datahelpdesk.worldbank. org/knowledgebase/articles/906519-world-bank-country-and-lending-groups. Accessed 12, July 2019.

12. Portnoy A, Jit M, Lauer J, et al. Estimating costs of care for meningitis infections in low- and middle-income countries. Vaccine. 2015;33(suppl 1):A240-A247.

13. Garg P, Krishak R, Shukla DK. NICU in a community level hospital. Indian J Pediatr. 2005;72:27-30.

14. Atif ML, Sadaoui F, Bezzaoucha A, et al. Prolongation of hospital stay and additional costs due to nosocomial bloodstream infection in an Algerian neonatal care unit. Infect Control Hosp Epidemiol. 2008;29:1066-1070.

15. Liao X-P, Chipenda-Dansokho S, Lewin A, et al. Advanced neonatal medicine in China: a national baseline database. Simeoni U, editor. PLoS One. 2017;12:e169970.

16. Qian L, Liu C, Zhuang W, et al; Chinese Collaborative Study Group for Neonatal Respiratory Diseases. Neonatal respiratory failure: a 12-month clinical epidemiologic study from 2004 to 2005 in China. Pediatrics. 2008; 121:e1115-e1124.

17. Balada-Llasat JM, Rosenthal N, Hasbun R, et al. Cost of managing meningitis and encephalitis among infants and children in the United States. Diagn Microbiol Infect Dis. 2019;93:349-354.

18. Balamuth F, Weiss SL, Neuman MI, et al. Pediatric severe sepsis in U.S children's hospitals. Pediatr Crit Care Med. 2014;15:798-805.

19. Bhatt P, Lekshminarayanan A, Donda K, , et al. Trends in incidence and outcomes of gastroschisis in the United States: analysis of the national inpatient sample 2010-2014. Pediatr Surg Int. 2018;34:919-929.

20. Davis KL, Bell TJ, Miller JM, et al. Hospital costs, length of stay and mortality associated with childhood, adolescent and young adult meningococcal disease in the US. Appl Health Econ Health Policy. 2011;9:197-207.

21. Donovan EF, Sparling K, Lake MR, et al; Ohio Perinatal Quality Collaborative. The investment case for preventing NICU-associated infections. Am J Perinatol. 2013;30:179-184.

22. Hartman ME, Linde-Zwirble WT, Angus DC, et al. Trends in the epidemiology of pediatric severe sepsis*. Pediatr Crit Care Med. 2013;14:686-693.

23. Iñigo J, Sendra JM, Díaz R, et al. [Epidemiology and costs of severe sepsis in Madrid. A hospital discharge study]. Med Intensiva. 2006;30:197-203.

24. Johnson TJ, Patel AL, Jegier BJ, et al. Cost of morbidities in very low birth weight infants. J Pediatr. 2013;162:243.e1-249.e1.

25. Lieu TA, Baskin MN, Schwartz JS, et al. Clinical and cost-effectiveness of outpatient strategies for management of febrile infants. Pediatrics. 1992;89(6, pt 2):1135-1144.

26. Robinson CJ, Villers MS, Johnson DD, et al. Timing of elective repeat cesarean delivery at term and neonatal outcomes: a cost analysis. Am J Obste Gynecol. 2010;202:632.e1-632.e6.

27. Tanihara S, Imatoh T, Momose Y. Assessment of medical expenditures for sepsis:differentiating between cases with and without ruled-out diagnoses. Acta Med Okayama. 2014;68:1-6.

28. Trevejo RT, Courtney JG, Starr M, et al. Epidemiology of salmonellosis in California, 1990-1999: morbidity, mortality, and hospitalization costs. Am J Epidemiol. 2003;157:48-57.

29. Uribe-Leitz M, McCracken CE, Heiss KF, et al. The influence of infectious complications in gastroschisis on costs and length of stay. Am J Perinatol. 2017;34:62-69.

30. Willson DF, Landrigan CP, Horn SD, et al. Complications in infants hospitalized for bronchiolitis or respiratory syncytial virus pneumonia. $J$ Pediatr. 2003;143(5 suppl):S142-S149.

31. World Health Organization. WHO | Data, statistics and graphics [cited August 13, 2019]. Available at: http://www.who.int/immunization/monitoring_surveillance/data/en/. Accessed 12, July 2019.

32. Arefian H, Heublein S, Scherag A, et al. Hospital-related cost of sepsis: a systematic review. J Infect. 2017;74:107-117.

33. Fitchett EJA, Seale AC, Vergnano S, et al; SPRING (Strengthening Publications Reporting Infection in Newborns Globally) Group. Strengthening the Reporting of Observational Studies in Epidemiology for Newborn Infection (STROBE-NI): an extension of the STROBE statement for neonatal infection research. Lancet Infect Dis. 2016;16:e202-e213.

34. Husereau D, Drummond M, Petrou S, et al; CHEERS Task Force Consolidated Health Economic Evaluation Reporting Standards (CHEERS) statement. BMJ. 2013;346:f1049

35. Vassall A, Sweeney S, Kahn J, et al. GHCC | Global heath cost consortium. [cited July 11, 2019]. Available at: https://ghcosting.org/pages/standards reference_case. Accessed 12, July 2019. 